\title{
A Bi-Level Model for Green Freight Transportation Pricing Strategy Considering Enterprise Profit and Carbon Emissions
}

\author{
Danzhu Wang ${ }^{1}$, Lingyun Zhou ${ }^{1, *}$, Huimin Zhang $^{2}$ and Xiaokang Liang ${ }^{3}$ \\ 1 Transportation \& Economics Research Institute, China Academy of Railway Sciences Corporation Limited, \\ Beijing 100081, China; wangdanzhu@rails.cn \\ 2 State Key Laboratory of Rail Traffic Control and Safety, Beijing Jiaotong University, Beijing 100044, China; \\ Huiminzhang@bjtu.edu.cn \\ 3 Passenger Transport Department, China State Railway Group Corporation Limited, Beijing 100844, China \\ 1xk868868@163.com \\ * Correspondence: zhoulingyun@rails.cn
}

Citation: Wang, D.; Zhou, L.; Zhang, H.; Liang, X. A Bi-Level Model for Green Freight Transportation Pricing Strategy Considering Enterprise Profit and Carbon Emissions. Sustainability 2021, 13, 6514. https://doi.org/10.3390/su13126514

Academic Editors: Fengxiang Qiao and Dong $\mathrm{Mu}$

Received: 25 March 2021

Accepted: 14 May 2021

Published: 8 June 2021

Publisher's Note: MDPI stays neutral with regard to jurisdictional claims in published maps and institutional affiliations.

Copyright: (C) 2021 by the authors. Licensee MDPI, Basel, Switzerland. This article is an open access article distributed under the terms and conditions of the Creative Commons Attribution (CC BY) license (https:/ / creativecommons.org/licenses/by/ $4.0 /)$.

\begin{abstract}
Due to the impact of COVID-19, enterprises need effective pricing strategies to improve profits and viability. In order to fill research gaps in the literature relating to market competition among different freight modes and to adjust the freight transportation structure by optimizing transportation prices, we propose a multi-objective bi-level programming pricing model that considers market competition and the carbon emissions of the freight system in China. First, an objective function in upper-level planning was used to improve logistics enterprise profits and reduce the total carbon emissions of the freight system. Then, a generalized cost function for the freight transportation mode was designed to quantify the market competition among different transportation modes, and a user equilibrium assignment model was established to obtain the results of cargo flow assignment in lower-level planning. To solve the model, a sensitivity analysis algorithm was designed, and a logistics network example was used to verify the effectiveness of the model. The experimental results show that reasonable freight price adjustment can effectively increase enterprise profits and reduce the total carbon emissions of the freight system. In this paper, we provide a new method for freight pricing research, considering the market competition of multiple transportation modes, and provide a new idea for adjusting the transportation structure through freight price optimization, which will play a positive role in promoting the development of green freight.
\end{abstract}

Keywords: transportation cost; carbon emission; competitiveness; pricing strategy; bi-level programming

\section{Introduction}

In 2020, COVID-19 had a serious impact on the international political and economic situation. The global supply chain was affected to varying degrees, and higher requirements for cost control and chain safety and reliability were recommended for the logistics system, generally. At the same time, with increases in global warming, the highest temperature in Antarctica exceeded $20^{\circ} \mathrm{C}$ in 2020, and ecological environment protection and green development have become priorities for all sectors of society. Modern transportation has become an important economic activity. Carbon emissions from transportation account for more than $20 \%$ of global carbon dioxide emissions, most of which come from fossil fuels [1]. In recent years, the contribution of China's transportation industry's carbon dioxide emissions has increased to $18-20 \%$ of China's total carbon emissions [2]. Hence, when considering carbon emissions, it is necessary to study the pricing strategy for green freight transportation in order to adjust the transportation structure and optimize the logistics costs of the supply chain system.

Due to the large-scale spread of COVID-19, the operating costs of some logistics enterprises are rising, and, at the same time, their income is falling (see Section 3.1 for 
data analysis). In order to improve the profitability of logistics enterprises and promote the green development of freight transportation, we propose a pricing method for freight transportation enterprises that considers their operating profit, the competition between different transportation modes, and the total carbon emissions of the transportation system. For this paper, the pricing method for railway express freight transportation has been studied in particular. However, the contemporary literature shows that it is rare to use a bi-level programming model to study pricing problems for railway express freight transportation. In addition, considering market competition, enterprise profits, carbon emissions, and carbon emission charges for one freight transport pricing model is relatively rare.

In order to solve freight transportation pricing problems while also considering enterprise profits and carbon emissions, we compared and analyzed the applicability of game theory, a dynamic pricing method, a bi-level programming model, and other optimization models in pricing problem research. Then, combined with the characteristics and application scope of the bi-level programming model, we used it to solve the pricing problem that considers market competition and the carbon emissions of the freight system in this paper. Referring to the relevant literature and inspired by the generalized cost function for passenger transport planning models, a generalized cost function for different transportation modes and a user behavior selection model were designed. From the literature review analysis to the model and method selection, parameter design, and example analysis, the research process for this paper is presented in Figure 1.

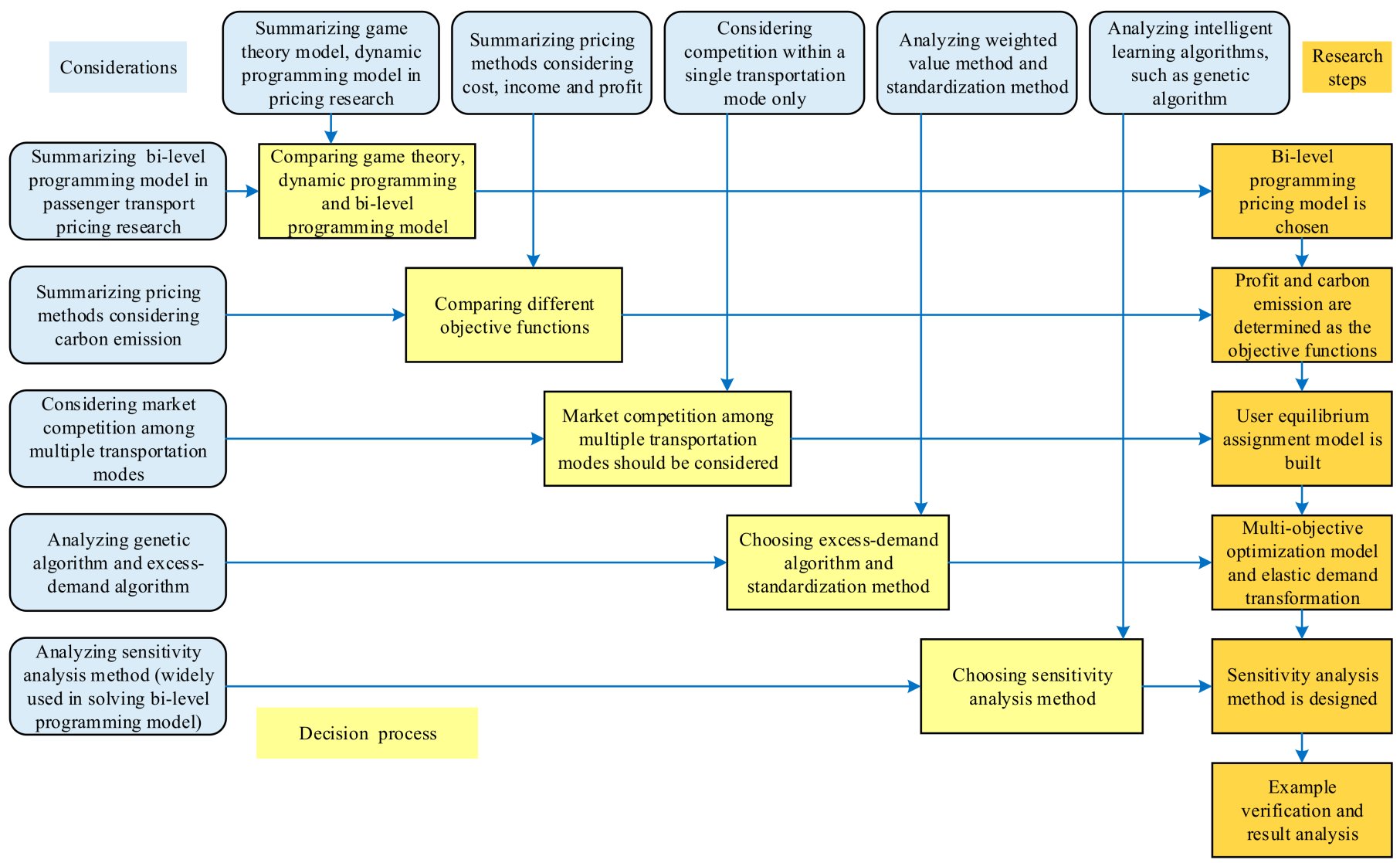

Figure 1. Research process of multi-objective bi-level programming model construction. Source: own elaboration.

\section{Literature Review}

\subsection{Comparative Analysis of Different Pricing Methods}

In order to find a suitable pricing model, we have extensively studied the literature on passenger transportation pricing, freight transportation pricing, and logistics pricing. In existing studies, many optimization models have been used in the study of transportation 
pricing, such as the game theory model, the dynamic programming model, and the bi-level programming model.

In their application of the game theory model, Wang et al. [3] considered the competitive relationship between different ports and proposed a port services pricing model based on game theory, with the goal of maximizing port enterprise profits. In their study, they established a user choice behavior model of port services, which provided an appropriate reference value for this paper in order to build a cargo flow assignment model. However, their research failed to consider the competitive relationship between different transportation modes. Xiao and Liu [4] proposed a game theory model to study the pricing strategy for maritime transportation costs, considering revenue management factors and the usage of empty containers. They considered the influence of transportation costs, the subjective values assigned to the containers by the owners, the arrival rate of owners, and changes in initial container slot allocation on the pricing of shipping enterprises, which provided a reference for the design of the generalized cost function for different freight modes used in this paper. Arbib et al. [5] established a three-level non-capacitated location/pricing problem, in which the pricing strategies of different suppliers were considered first, and the decisions of customers were considered second. They set the maximizing of enterprise profit as the optimization objective, but in the process of solving the model, some enterprises (such as enterprise A) needed to make price decisions first and then other enterprises were able to adjust their own pricing according to the price strategies of enterprise A.

In the application of a dynamic pricing method considering competition, Song et al. [6] proposed an optimization model of dynamic pricing for a high-speed railway, which considered the passenger flow demand in different ticket periods. However, in their model, only the influence of railway passenger transport in different transport periods is considered; the competitive relationship between railway, highway, and air transportation is not considered. This kind of pricing method cannot improve the traffic volume of a specific transportation mode in competition with different transportation modes. Zeng et al. [7] studied the relationship between market demand, logistics enterprise pricing, and pricematching coefficients. Then, the effect of logistics enterprise pricing on shipper booking cost was tested and analyzed. The authors considered the relationship between freight volume and transportation price. However, from a macro perspective, the competition among different transportation modes has not yet been investigated.

Through a detailed analysis of the game theory model and dynamic pricing model, we found that these two models cannot fully reflect market competition among different transportation modes. Therefore, in the next section, we summarize and analyze the bi-level programming model, considering passenger transport pricing.

\subsection{Analysis of Bi-Level Programming Model in Transportation Pricing}

In the application of various optimization models, the bi-level programming model has widely been used in the study of passenger ticket pricing [8]. The logit model and the improved disaggregated multivariate logit model have often been used to establish the user equilibrium assignment model of passenger travel behavior [9-11]. The sensitivity analysis method, fuzzy mathematics method, particle swarm optimization, simulated annealing, and other heuristic algorithms have commonly been used in the study of product pricing model solving [12]. In the modeling of specific problems, Tuffin et al. [13] proposed a product pricing strategy based on satisfaction maximization. They considered the influence of elastic demand level on revenue maximization, which is an effective way to reflect market competition. Ren et al. [14] introduced a finite-state Markov chain to capture the traffic flow dynamics of users and constructed a resource-free congestion pricing model. With increasing attention being paid to energy conservation and emission reduction, Thomas and Frank [15] studied how to solve the environmental protection problem for highway and railway transportation system design from the perspective of reducing greenhouse gas emissions. Chen and Yang [16] discussed the relationship between traffic system carbon emissions and road network congestion, and established a corresponding bi-objective 
programming model. Zhang and Li [17] considered the correlation between pricing and operation planning strategies, proposing a bi-level model in which the lower level was designed to minimize the customer's general cost, and the upper level was designed to maximize the revenue of rail operators. The model established in their study provided an appropriate reference value for this paper. Yu et al. [18] proposed a bi-level programming model for an airline's hub-and-spoke route network design. The locations of hub airports and the selection of both subsidy schemes for aviation markets and O\&D passenger flow itineraries were considered as decision variables in the upper-level model, and the pricing decision of market subsidies for each civil aviation transportation airport was treated as the lower-level model. Zhang et al. [19] proposed an improved optimization model that encompassed pricing, carbon emissions, operation planning, and service queuing for an infinite horizon decision process. Jia et al. [20] proposed a rule-based method (used in complex engineering systems) for automated surrogate model selection, and designed a genetic algorithm (GA) to find the appropriate hyperparameters for each selected surrogate model. A detailed literature review of the computational complexity of complex system problems was provided in [21]. Based on their research results, combined with the applicability and convenience of the heuristic algorithm and sensitivity analysis method, we chose the sensitivity analysis method to solve our model.

\subsection{Analysis of Green Pricing Method Considering Carbon Emissions}

In terms of pricing strategy, and considering the impact of carbon emissions, Chang et al. [22] developed a road pricing model that considered the government, the perspectives of road users, and the ETC (Electronic Toll Collection) agent, seeking to attain greener transportation by leveraging the external costs related to environmental impact and accident potential. This provided an appropriate reference for the design of carbon emission charging parameters in this paper. Saharan et al. [23] presented a detailed review on the application of dynamic pricing technology in a modern intelligent transportation system (ITS). In their study, different evaluation parameters, limitations, and applications of different dynamic pricing techniques were discussed in depth. Williams et al. [24] considered the impact of carbon emissions and studied the design method for a green supply chain system. They built a model of a GSC based on population data, and conducted a sensitivity analysis to study the effect of a carbon tax to encourage a greener system design. A similar study was carried out in [25]. Their design idea for a green supply chain model and the analysis of a carbon tax on greenhouse gas emissions provided an appropriate reference for our study. Han et al. [26] comprehensively analyzed the carbon emissions of China during the period of the COVID-19 pandemic. They studied in detail the relationship between the carbon emissions of the transportation industry and freight/passenger transportation. Their research showed that reasonable adjustment of carbon emissions from the transportation industry was of great significance for reducing national greenhouse gas emissions and promoting green development. This is also one of the main considerations for our study - to demonstrate the impact of greenhouse gas emissions on the pricing of a green freight transportation system. Research in the same field has also been comprehensively analyzed by the authors of [27], who further analyzed the impacts of COVID-19 on global emissions and the Paris Agreement.

Based on the existing research results, we established a multi-objective bi-level programming model for green freight transportation pricing, considering the factors of greenhouse gas emissions, logistics revenue, transportation time, service level, logistics chain reliability, and so forth, in order to provide theoretical support and a reference method for green freight transportation pricing strategy selection in supply chain and logistics enterprises.

\section{Influence of COVID-19 and Carbon Emissions on the Choice of Freight Transportation Mode}

The spread of COVID-19 has brought disastrous consequences to the world. The medical systems of cities with serious pandemic situations have encountered great pressure and challenges $[28,29]$, and the impact on global economic development, food and health, 
and energy supplies is incalculable [30-32]. In order to fully understand the impact of COVID-19 on global economic development, transportation demand and cost, transportation stability and reliability, and transportation greenhouse gas emissions, in this section, we present a detailed analysis from the above perspectives.

\subsection{Transportation Demand and Cost}

From the macro-economic point of view, due to the prevalence of COVID-19, the downward pressure of the global economy is increasing. According to the forecast of the International Monetary Fund (IMF) in the April 2021 World Economic Outlook, the growth rate of the global economy in 2020 was $-3.3 \%$ [33]. This economic recession is far more severe than the economic downturn caused by the international financial crisis in 2008. After the international financial crisis in 2008, the growth rate of the world economy in 2009 was $-0.6 \%$, which is far less than the impact of COVID-19 on the global economy in 2020 [34].

From the perspective of the international transportation industry, the IATA Annual Review 2020, released by the International Air Transport Association (IATA), shows that, in 2020, global air cargo ton-kilometers (CTKs) dropped by $11.5 \%$ year-on-year [35], which is the largest drop since 1990 (since the beginning of IATA statistics).

In terms of transportation costs, due to the economic downturn, the capital chain of enterprises has been seriously impacted, and sensitivity to transportation costs has significantly enhanced. Alexandre de Juniac, IATA's chairman and Chief Executive, said the crisis had dealt a merciless and devastating blow to the industry, with airlines cutting costs by $45.8 \%$, but revenue by $60.9 \%$ [36]. Therefore, when choosing the transportation mode, logistics enterprises will pay more attention to the logistics cost. It is necessary to select the minimum logistics cost and the maximum logistics revenue as one of the optimization objectives of green freight system pricing to improve the business situation of enterprises.

\subsection{Reliability and Stability}

In terms of the impact on supply chain stability, COVID-19 has caused the interruption of supply chains throughout the world, which has created great challenges to global supply chain management. Many researchers are concerned about how best to manage the supply chain disruptions caused by COVID-19, including suppliers, manufacturers, and retailers [37]. At the same time, the integration ability, resilience, and sustainability of the world's supply chains are facing great challenges; a lot of research has been carried out on the sustainability of supply chains [38,39]. A systematic study was carried out by Sarkis [40]; this study provided research guidance for investigating sustainability in supply chains in a post-COVID-19 environment, and theoretical support for environmental, social, and economic sustainability in the post-pandemic period. In summary, how to best help enterprises rebuild their supply chains has become one of the main concerns of scholars.

From the perspective of the domestic transportation industry, concerning China's freight transportation market, in 2020, air freight was the most volatile, with a $10.2 \%$ drop in freight volume, followed by a 3.3\% drop in waterway transportation, and a $0.3 \%$ drop in road transportation. Railway freight was the least affected, achieving a 3.2\% growth, as shown in Table 1 [41]. The fluctuation of freight volume can reflect that in the face of the impact of the pandemic, railway transportation had obvious advantages in terms of stability and reliability, followed by highway transportation. Air transportation was the most affected, with relatively poor stability and reliability. 
Table 1. Freight volumes and growth rates for different transportation modes in 2020.

\begin{tabular}{cccc}
\hline Index & Unit & Absolute Number & Year-on-Year Increase (\%) \\
\hline Total freight volume & 100 million tons & 463.4 & -0.5 \\
Railway & 100 million tons & 44.6 & 3.2 \\
Highway & 100 million tons & 342.6 & -0.3 \\
Waterway & 100 million tons & 76.2 & -3.3 \\
Air freight & 10,000 tons & 676.6 & -10.2 \\
\hline
\end{tabular}

Source: China National Bureau of Statistics website.

From Figure 1 we can see that railway transportation is least affected by external environment, meaning its transportation stability is the highest among modes. Air transport is most affected by external factors, and its stability is relatively low. The stability of highway transportation is moderate.

\subsection{Carbon Emissions}

Global warming threatens all life on Earth. An increasing number of natural disasters are closely related to global climate change. From the impact of COVID-19 on the global environment and economy, the COVID-19 crisis may inform environmental research related to globalization and cooperation, the green transition, and pricing carbon externalities, as well as the role of uncertainty and timing of policy inventions [42]. In order to protect the ecological environment, China aims to adopt more effective policies and measures, strives to make carbon dioxide emissions reach their peak by 2030, and strives to achieve carbon neutrality by 2060. As transportation is one of the important energy consumption and carbon emissions industries, effective control of its carbon emissions plays an important role in protecting the natural environment and suppressing climate warming. The energy consumption and the proportion of energy consumption in China's transportation industry are shown in Figure 2 [43].

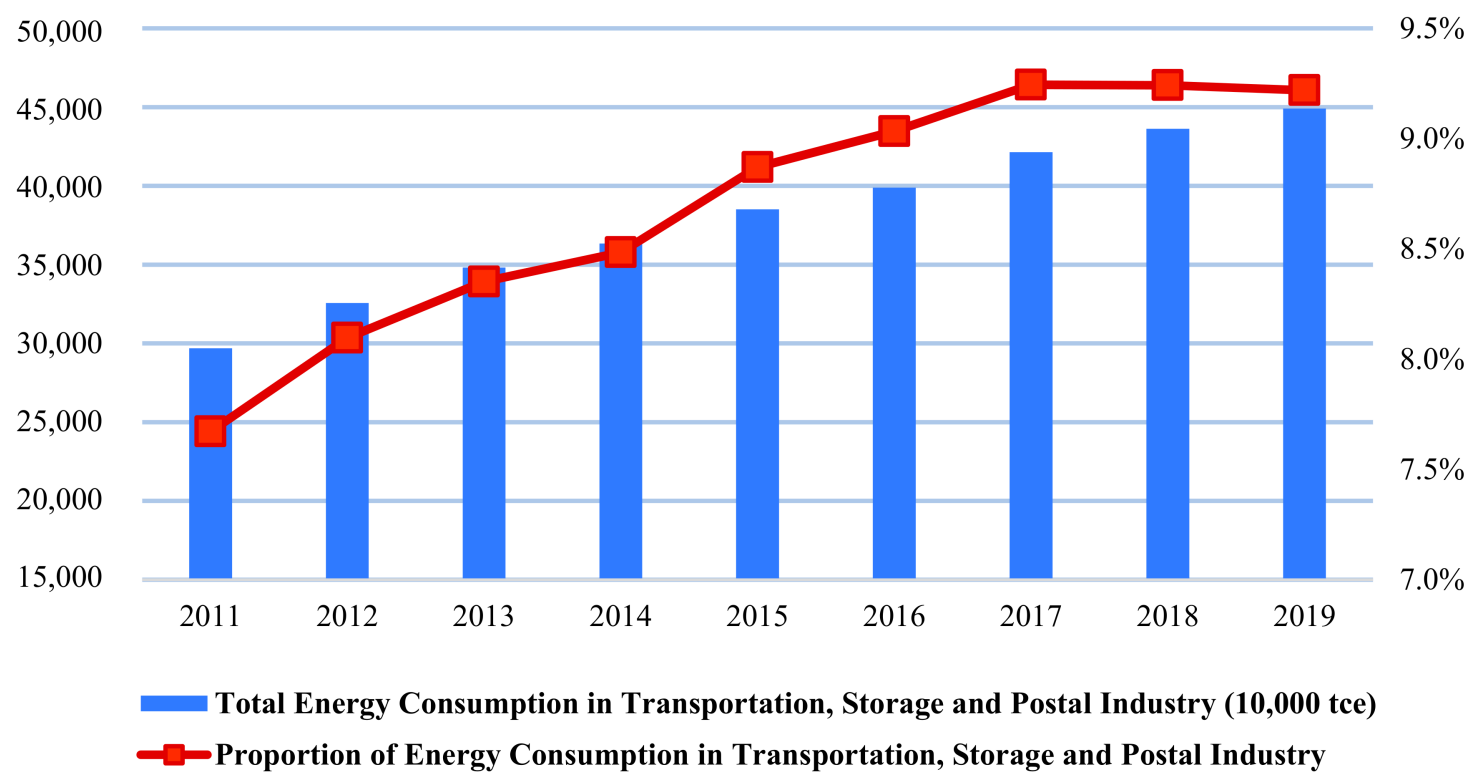

Figure 2. Total energy consumption in transportation, storage, and the postal industry and its proportion. Source: China Energy Statistical Yearbook.

In general, adjusting the transportation structure and optimizing the distribution of freight flow among different transportation modes are among the ways of reducing carbon emissions in the transportation industry. However, reducing the use of fossil energy is one of the most important ways of reducing global warming and greenhouse gas emissions. Shifting from fossil to clean energy sources is a major global challenge, 
especially for the transportation industry (which accounts for a relatively high proportion of greenhouse gas emissions). The active development of bioenergy and other clean energy sources is an effective way to reduce transportation's greenhouse gas emissions. The literature $[44,45]$ contains systematic research that applies bioenergy and other clean energy to reduce greenhouse gas emissions. The studies [46-48] analyzed how to increase the performance of complex electricity generation systems and BIM-based building projects, and how to reduce environmental costs through logistics optimization. Their research results contribute important reference values to promote the green development of the transportation industry in future research and provide some methods for the development of green freight transportation.

\section{Modeling}

\subsection{Decision-Making Objectives}

In order to effectively control carbon emissions in the transportation industry, a multi-objective bi-level programming model for green freight transportation pricing was established based on elastic demand, and the competition among different modes of highway, railway, and air transportation was considered. In this model, upper-level planning describes the decision-making objectives of maximizing enterprise revenue and minimizing system carbon emissions; lower-level planning describes the distribution mode of freight demand among highway, railway, and air transportation modes under competitive conditions.

Equation (1) is the decision-making objective, which is the profit maximization of logistics enterprises, including freight volume, freight transportation price, freight transportation cost, carbon emission charges, and the transportation distance of different transportation modes. Equation (2) is the constraint condition of the freight price parameter, which is between the upper limit and the lower limit of the freight price of a certain transportation mode. The formula of the objective function is as follows:

$$
\begin{aligned}
\max F_{1} & =\sum_{w \in W} q_{n}^{w} \cdot\left(p_{n}^{w}-c_{n}^{w}-\gamma_{(n)}^{w}\right) \cdot l^{w} \\
\text { s.t. } & p_{n}^{w(\min )} \leq p_{n}^{w} \leq p_{n}^{w(\max )}
\end{aligned}
$$

where $F_{1}$ is the decision-making objective of maximizing the profit of the logistics enterprises. $n \in N, N=\{1,2,3\}$ represents the transportation mode $n$, and $N$ is the set of transportation modes; $n=1$ represents the railway transportation mode, $n=2$ represents the highway transportation mode, and $n=3$ represents the air transportation mode. $w \in W$ is the number of an OD pair (a pair of one origin point and one destination point, Order Description), and $W$ is the set of OD pairs. $q_{n}^{w}\left(q_{n}^{w} \geq 0\right)$ is the freight volume of transportation mode $n ; \sum_{n \in N} q_{n}^{w}=Q_{N}^{w} \cdot Q_{N}^{w}$ is the total freight volume of the transportation system. $p_{n}^{w}$ is the price of transportation mode $n . c_{n}^{w}$ is the average transportation cost of transportation mode $n . l^{w}$ is the distance between OD pair $w . p_{n}^{w(\min )}$ represents the average transportation cost of the logistics enterprise (including the cost of carbon emission charges). $p_{n}^{w(\max )}$ is the upper limit of the price $p_{n}^{w} \cdot \gamma_{(n)}^{w}$ is the cost of carbon emission charges for different transportation modes, which are charged according to different charging standards that correspond to the total freight volume of different transportation modes in a fixed period. $\gamma_{(n)}^{w}$ is a piecewise function of $q_{n}^{w}$, expressed as follows. For analysis of the impact of carbon emission charges on greenhouse gas emissions, see reference [24]; this impact can be obtained by Equation (3).

$$
\gamma_{(n)}^{w}=\left\{\begin{array}{c}
\gamma_{1} 0 \leq q_{n}<a \\
\gamma_{2} a \leq q_{n}<b \\
\gamma_{3} b \leq q_{n}
\end{array}\right.
$$


where $\gamma_{1}, \gamma_{2}$, and $\gamma_{3}$ are fixed parameters of the charging standard. $a$ and $b$ are fixed parameters of freight volume, which can be converted into energy consumption according to energy intensity parameters and the carbon emissions coefficient. The parameter values are determined according to the total carbon emissions of different transportation modes; we refer to the carbon emissions charging model in [25]. The introduction of carbon emission charge $\gamma_{(n)}^{w}$ is mainly to effectively adjust the transport structure, optimize the carbon emissions of the freight system, and promote environmental protection. The purpose of carbon emissions charging is to limit the freight volume of the high-emission transportation mode and promote the development of a green transportation mode.

To minimize the carbon emissions of the green freight transportation system, the government should actively promote the adjustment of the transportation structure. In our study, the energy consumption of different transportation modes $J_{n}^{w}$ is converted into a kilogram of standard coal equivalent (kgce); this can be calculated by Equation (4). Equation (4) includes the following factors: energy consumption factor, freight volume, and the transportation distance of different transportation modes.

$$
J_{n}^{w}=\theta_{n} \times q_{n}^{w} \times l^{w} \times 10^{-4},
$$

where $J_{n}^{w}$ is the energy consumption of the transportation mode $n$, and its unit is kgce. $\theta_{n}$ is the energy consumption factor of the transportation mode $n$, and its unit is kgce $/ 10^{4}$ $\mathrm{t} \cdot \mathrm{km} . l^{w}$ is the transportation distance of OD pair $w$, and its unit is $\mathrm{km}$. With reference to China's traffic energy intensity setting requirements for different transportation modes, we set $\theta_{1}=85.4, \theta_{2}=566.7$, and $\theta_{3}=5168.8$. Assuming that the conversion ratio of $2.6 \mathrm{t} \mathrm{CO}_{2}$ emissions from $1 \mathrm{t}$ of standard coal consumption, we set the carbon emissions factor to $\delta_{c}=2.6$; then, the total carbon emissions of different transportation modes can be calculated. The objective function for minimizing the carbon emissions of the green freight transportation system can be obtained as follows:

$$
\begin{gathered}
\min F_{2}=\sum_{w \in W} \sum_{n \in N} \delta_{c} J_{n}^{w} \\
\text { s.t. } q_{n}^{w} \geq 0
\end{gathered}
$$

Equation (5) is the objective function for minimizing carbon emissions of the green freight transportation system; it includes the carbon emissions factor and the energy consumption of the transportation mode. Equation (6) is the constraint of the objective function, which is where the freight volume of each transportation mode is greater than or equal to 0 .

\subsection{User Selection Model}

Considering the price competition of different transportation modes, the freight demands decrease with an increase in generalized cost; the different transportation modes will reach a stable equilibrium state-the freight flow distribution equilibrium - which conforms to Wardrop's first principle. We use $Q_{N}^{w}=\alpha_{O} \beta_{D} h\left(\mu_{\min }^{w}\right)$ as the demand function. $\alpha_{O}$ and $\beta_{D}$ represent the related parameters of the origin node and destination node of the OD pair, respectively. $h\left(\mu_{\min }^{w}\right)$ is a function of $\mu_{\min }^{w}$; generally, $h(*)$ is a monotonically decreasing function (at least not monotonically increasing) - it needs to meet the condition that if $\mu_{\min }^{w}$ increases, $Q_{N}^{w}$ will decrease. The following mathematical programming model is used to describe the distribution of freight flow among different transportation modes:

$$
\begin{gathered}
(\mathrm{P} 1-1) \min Z\left(q_{n}^{w}, Q_{N}^{w}\right)=\sum_{w \in W} \sum_{n \in N} \int_{0}^{q_{n}^{w}} f_{n}^{w}(x) d x-\sum_{w \in W} \int_{0}^{Q_{N}^{w}} D_{w}^{-1}(x) d x \\
\text { s.t. } \sum_{n \in N} q_{n}^{w}=Q_{N}^{w} \quad n \in N, w \in W \\
q_{n}^{w} \geq 0 \quad n \in N, w \in W
\end{gathered}
$$


where function $f_{n}^{w}(x)$ is the generalized cost function for the transportation mode $n$, which is on the monotonic increase in freight volume $q_{n}^{w}$, and we set $C_{n}^{w}=f_{n}^{w}\left(q_{n}^{w}\right),(n \in$ $N, w \in W) . D_{w}^{-1}(x)$ is the inverse function of the freight demand function, which is on the monotonic decrease in total freight demand $Q_{N}^{w}$.

Equation (7) is the objective function for user-generalized cost minimization, which can be calculated by the generalized cost function of the transportation mode and the inverse function of the freight demand function. Equations (8) and (9) are constraints. Constraint (8) is the sum of the freight volume of all transportation modes being equal to the total freight volume. Constraint (9) is the freight volume of each transportation mode being greater than or equal to 0 .

In the model, Equation (7) is strictly convex with respect to freight demand, and the solution space of Model (P1-1) is a convex set because Constraint (8) is linear, and Constraint (9) is nonnegative. According to the optimization principle, a strictly convex function defined on a convex set has a unique optimal solution.

\subsection{Generalized Cost Function for Different Transportation Modes}

The generalized cost is the tangible and intangible consumption of producers in the whole process of production and operation. The generalized cost function for the freight service should include rapidity, punctuality, safety, economy, convenience, service level, and the environmental impact of the transportation process. For this paper, the inverse demand function was selected as the generalized cost function for different transportation modes, and the exponential demand function was selected as the function type of the generalized cost function: $q_{n}^{w}=\exp \left\{\tau\left(C_{n}^{w}+L_{n}^{w}\right)\right\},(n \in N, w \in W)$, where $C_{n}^{w}$ represents the generalized cost of the cargo owner choosing the transportation mode $n$; $L_{n}^{w}$ is the utility function of the transportation mode $n ; \tau$ is a pending parameter. Additionally, there is $L_{n}^{w}=\sum_{i=1}^{m} \alpha_{n}^{i} x_{n}^{i}, i=1,2, \ldots, m ; n \in N ; w \in W$, where $i$ is the transport attribute of transportation mode $n$ between OD pair $w, i=1,2, \ldots, m ; m$ is the total number of transport attributes of transportation mode $n ; x_{n}^{i}$ indicates the transportation attribute value $i$ of transportation mode $n$ (such as transportation time, convenience, safety, etc.); $\alpha_{n}^{i}\left(\alpha_{n}^{i} \geq 0\right)$ is a pending parameter. Then, the inverse demand function is obtained as $D_{w}^{-1}\left(q_{n}^{w}\right)=\frac{1}{\tau} \ln q_{n}^{w}-L_{n}^{w}, n \in N, w \in W$. The basic form of the generalized cost function of different transportation modes is as follows: $f_{n}^{w}\left(q_{n}^{w}\right)=\frac{1}{\tau} \ln q_{n}^{w}-L_{n}^{w}, n \in N, w \in W$.

For railway transportation, we took railway express freight transportation as the example with which to study the pricing strategy of a green freight system. In the selection of railway transportation parameters, the model parameters were designated based on the relevant parameters of railway express freight trains; for example, we set the speed of railway transportation to $v_{1}=110 \mathrm{~km} / \mathrm{h}$. For the railway transportation of bulk goods, it is usually difficult to reach this speed.

There are also many factors influencing the utility function: (1) Average freight rate $p_{n}^{w}$, unit CNY $/ \mathrm{t} \cdot \mathrm{km}$. (2) Rapidity: $T_{n}^{w}=t_{n}+l^{w} / v_{n}$, unit h (hour), where $t_{n}$ is the average pickup and delivery time, and the values are $t_{1}=3 \mathrm{~h}, t_{2}=1 \mathrm{~h}, t_{3}=4 \mathrm{~h}$; $l^{w}$ is the transportation distance of the OD pair $w . v_{n}$ is the transport speed of the transportation mode $n$, assuming $v_{1}=110 \mathrm{~km} / \mathrm{h}, v_{2}=80 \mathrm{~km} / \mathrm{h}$ (speed limit of expressways in China), $v_{3}=900 \mathrm{~km} / \mathrm{h}$. (3) Safety: $D_{n}$ is the cargo damage rate, assuming $D_{1}=0.002, D_{2}=0.004$, $D_{3}=0.001$. (4) Punctuality: $G_{n}$ is overdue rate; $G_{n}=g_{n}^{*} / g_{n}^{\text {total }}$, where $g_{n}^{*}$ represents the batch of overdue goods among the total batches of goods transported by mode $n$, $g_{n}^{\text {total }}$ represents the total batches of goods transported by mode $n$. (5) Convenience $E_{n}$ is considered in stages: $\leq 300 \mathrm{~km}, E_{1}=0.1, E_{2}=1, E_{3}=0 ; 300 \sim 500 \mathrm{~km}, E_{1}=0.5, E_{2}=1$, $E_{3}=0 ; 500 \sim 2000 \mathrm{~km}, E_{1}=0.75, E_{2}=0.85, E_{3}=0.9 ; 2000 \sim 3500 \mathrm{~km}, E_{1}=0.6, E_{2}=0.2$, $E_{3}=0.9 ; \geq 3500 \mathrm{~km}, E_{1}=0.1, E_{2}=0, E_{3}=1$. (6) Service quality: $S_{n}$ can be obtained through customer survey statistics. (7) Environmental effect: $Y_{n}$. In this paper, we refer to the literature studies $[3,16,49]$ for the service level assessment of different transportation modes, and Equation (10) is the utility function for different transportation modes. 


$$
L_{n}^{w}=\alpha_{1} p_{n}^{w}+\alpha_{2} T_{n}^{w}+\alpha_{3}\left(1-D_{n}\right)+\alpha_{4}\left(1-G_{n}\right)+\alpha_{5} E_{n}+\alpha_{6} S_{n}+\alpha_{7} Y_{n}
$$

\subsection{Green Freight Transportation Pricing Model}

Model (P1-1) describes the sharing mode of freight demand among railway, highway, and air transportation between an OD pair. Further extending the research object from a single OD pair to the whole freight network, the transportation pricing problem in the whole logistics market can then be solved. The green freight transportation pricing model can be constructed as follows:

$$
\begin{gathered}
(\mathrm{M} 1-2) \max F_{\mathrm{I}}\left(p_{1}^{w}\right)=\sum_{w \in W} q_{1}^{w}\left(p_{1}^{w}\right) \cdot\left(p_{n}^{w}-c_{n}^{w}-\gamma_{(n)}^{w}\right) \cdot l^{w} \\
\min F_{\mathrm{II}}\left(p_{n}^{w}\right)=\sum_{w \in W} \sum_{n \in N} \delta_{c} \theta_{n} q_{n}^{w}\left(p_{n}^{w}\right) l^{w} \times 10^{-4} \\
\text { s.t. } p_{1}^{w(\min )} \leq p_{1}^{w} \leq p_{1}^{w(\max )} w \in W
\end{gathered}
$$

where the freight volume is $q_{n}^{w}\left(p_{n}^{w}\right)$. It is calculated by the lower-level programming model:

$$
\begin{aligned}
(\mathrm{L} 1-2) \min Z\left(q_{n}^{w}\right)= & \sum_{w \in W} \sum_{n \in N} \int_{0}^{q_{n}^{w}} f_{n}^{w}(x) d x-\sum_{w \in W} \int_{0}^{Q_{N}^{w}} D_{w}^{-1}(x) d x \\
\text { s.t. } & \sum_{n \in N} q_{n}^{w}\left(p_{n}^{w}\right)=Q_{N}^{w} w \in W \\
& q_{n}^{w} \geq 0 n \in N, w \in W
\end{aligned}
$$

Equation (11) is the objective function for enterprise profit maximization. Equation (12) is the objective function to minimize the carbon emissions of the whole green freight system. Equation (13) is the freight price constraint. Equation (14) is the objective function of user-generalized cost minimization. Equations (15) and (16) have the same meaning as Equations (8) and (9).

By solving the above model, we can obtain the optimal pricing strategy for a green freight transportation system under the given decision objectives.

\section{Model Transformation and Algorithm Design}

\subsection{Transformation of User Selection Model}

The common conversion methods for the objective function of the elastic demand model are the zero impedance additional flow method and the excess demand method. We used the excess demand method [50], introduced the fixed value of the upper limit of freight demand $Q_{\max }^{w}$, and took the difference between the total freight demand and the upper limit of freight demand-the excess demand as the bridge completes the transformation of the elastic demand objective function to the fixed demand objective function. When setting the excess demand $q_{\text {rest }}^{w}$ equal to the difference between the total freight demand $Q_{N}^{w}$ and the upper limit of freight demand $Q_{\max }^{w}$, this results in $q_{\text {rest }}^{w}=Q_{\max }^{w}-Q_{N}^{w}$. Additionally, by using the definite integral substitution method (see reference [50]), the objective function of the Model (P1-1) can be transformed into:

$$
\min Z\left(q_{n}^{w}, q_{r e s t}^{w}\right)=\sum_{w \in W} \sum_{n \in N} \int_{0}^{q_{n}^{w}} f_{n}(x) d x+\sum_{w \in W} \int_{0}^{q_{r e s t}^{w}} R(x) d x
$$

Equation (17) is the objective function for user-generalized cost minimization, which is transformed by the excess demand method. As the excess variable function $R(x)$ and the generalized cost function $f_{n}^{w}(x)$ have the same characteristics of composition and increase or decrease, in the process of solving, $R(x)$ can be regarded as the generalized cost function for excess freight demand $q_{\text {rest }}^{w}$. This means that a virtual transportation mode 
is added between OD pairs, which transforms the competition among the original three transportation modes into four transportation modes, as shown in Figure 3.

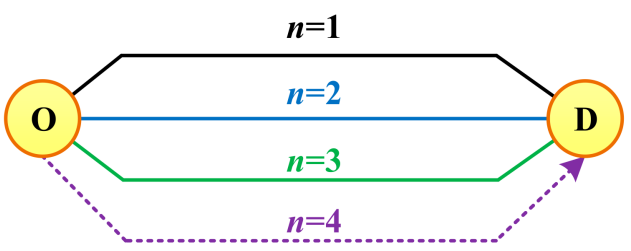

Figure 3. Transformation of elastic demand into fixed demand. Source: own elaboration.

In Figure 3, $n=1, n=2$, and $n=3$ represent the railway, highway, and air transportation modes, respectively, and $n=4$ represents the virtual transportation mode.

Assuming that the form of function $R\left(q_{\text {rest }}^{w}\right)$ is basically the same as that of the generalized cost function $f_{n}^{w}(x)$ of different transportation modes, the simplified lower-level model can be expressed as follows:

$$
\begin{gathered}
(\mathrm{L} 1-3) \operatorname{minZ}\left(q_{n}^{w}\right)=\sum_{w \in W} \sum_{n \in N^{*}} \int_{0}^{q_{n}^{w}} f_{n}^{w}(x) d x \\
\text { s.t. } \sum_{n \in N^{*}} q_{n}^{w}=Q_{\max }^{w} w \in W \\
q_{n}^{w} \geq 0 \quad n \in N^{*}, w \in W
\end{gathered}
$$

Equation (18) is the objective function for minimizing the sum of the four transportation modes. Equations (19) and (20) have the same meaning as Equations (8) and (9).

In Model (L1-3), $N^{*}$ means that an additional virtual transportation mode is added to the original transportation mode set; that is, the transportation mode set is changed to include $N+1$ transportation modes. The new virtual transportation mode is represented by $n=4$ in this paper, and the generalized cost function of the fourth transportation mode is $f_{4}^{w}\left(q_{4}^{w}\right)=R\left(q_{\text {rest }}^{w}\right)=D^{-1}\left(Q_{N}^{w}\right)$.

\subsection{Transformation of Multi-Objective Optimization Problems}

In general, the process of solving the multi-objective optimization problem (MOP) is to coordinate and trade off among various objectives, so as to make each objective function as optimal as possible. Considering that the two decision objectives of this model have different dimensions, we use the standardization method to standardize the two objective functions and convert them into the $[0,1]$ interval. The weights of the two objective functions are set to $\omega_{1}=-0.8$ and $\omega_{2}=0.2$. A new evaluation function $U\left(p_{1}^{w}\right)$ is constructed by using a standardization method. Then, we set:

$$
\min U\left(p_{1}^{w}\right)=\omega_{1} \cdot\left(\frac{F_{\mathrm{I}}\left(p_{n}^{w}\right)-F_{\mathrm{I}}^{\min }\left(p_{n}^{w}\right)}{F_{\mathrm{I}}^{\max }\left(p_{n}^{w}\right)-F_{\mathrm{I}}^{\min }\left(p_{n}^{w}\right)}\right)+\omega_{2} \cdot\left(\frac{F_{\mathrm{II}}\left(p_{n}^{w}\right)-F_{\mathrm{II}}^{\min }\left(p_{n}^{w}\right)}{F_{\mathrm{II}}^{\max }\left(p_{n}^{w}\right)-F_{\mathrm{II}}^{\min }\left(p_{n}^{w}\right)}\right)
$$

Equation (21) is the new objective function for enterprise profit maximization and system carbon emission minimization, which is transformed by the standardization method.

Then, the two decision-making objective functions in the upper-level programming model can be transformed into a new objective function, as per Equation (22):

$$
\min U\left(p_{1}^{w}\right)=-0.8 \cdot\left(\frac{\sum_{w \in W} q_{1}^{w}\left(p_{1}^{w}\right) \cdot\left(p_{n}^{w}-c_{n}^{w}-\gamma_{(n)}^{w}\right) \cdot l^{w}-F_{\mathrm{II}}^{\min }\left(p_{n}^{w}\right)}{F_{\mathrm{II}}^{\max }\left(p_{n}^{w}\right)-F_{\mathrm{II}}^{\min }\left(p_{n}^{w}\right)}\right)+0.2 \cdot\left(\frac{\sum_{w \in W} \sum_{n \in N} \delta_{c} \theta_{n} q_{n}^{w}\left(p_{n}^{w w}\right) l^{w} \times 10^{-4}-F_{\mathrm{I}}^{\min }\left(p_{n}^{w}\right)}{F_{\mathrm{I}}^{\max }\left(p_{n}^{w w}\right)-F_{\mathrm{I}}^{\min }\left(p_{n}^{w w}\right)}\right) n \in N, w \in W
$$

where $p_{1}^{w(\min )} \leq p_{1}^{w} \leq p_{1}^{w(\max )}$. In the process of solving function $F_{\mathrm{II}}\left(p_{n}^{w}\right)$, only $p_{1}^{w}$ is regarded as the variable to be solved; $p_{2}^{w}$ and $p_{3}^{w}$ are regarded as fixed values. Additionally, 
in the objective function $F_{\mathrm{II}}\left(p_{n}^{w}\right), n \in N$; that is, it does not include the virtual mode of transportation, so it does not involve the setting of $p_{4}^{w}$. After elastic demand transformation and MOP transformation, a new bi-level programming model is obtained as follows.

$$
\begin{gathered}
(\mathrm{M} 1-4) \min U\left(p_{1}^{w}\right)=0.2 \cdot \frac{\left.\sum_{w \in W} \sum_{n \in N} \delta_{c} \theta_{n} q_{n}^{w}\left(p_{n}^{w}\right)\right)^{w w} \times 10^{-4}-F_{\mathrm{I}}^{\min }\left(p_{n}^{w}\right)}{F_{\mathrm{I}}^{\max }\left(p_{n}^{w}\right)-F_{\mathrm{I}}^{\min }\left(p_{n}^{w}\right)}-0.8 \cdot \frac{\sum_{w \in W} q_{1}^{w}\left(p_{1}^{w}\right) \cdot\left(p_{n}^{w}-c_{n}^{w}-\gamma_{(n)}^{w}\right) \cdot l^{w}-F_{\mathrm{II}}^{\min }\left(p_{n}^{w}\right)}{F_{\mathrm{II}}^{\max }\left(p_{n}^{w w}\right)-F_{\mathrm{II}}^{\min }\left(p_{n}^{w}\right)} \\
\text { s.t. } p_{1}^{w(\min )} \leq p_{1}^{w} \leq p_{1}^{w(\max )} w \in W \\
p_{n}^{w} \geq 0 n \in N, w \in W
\end{gathered}
$$

where $\mathbf{q}(\mathbf{p})$ is given by the lower-level programming model:

$$
\begin{gathered}
(\mathrm{L} 1-4) \min Z\left(q_{n}^{w}\right)=\sum_{w \in W} \sum_{n \in N^{*}} \int_{0}^{q_{n}^{w}} f_{n}^{w}(x) d x \\
\text { s.t. } \sum_{n \in N^{*}} q_{n}^{w}\left(p_{n}^{w}\right)=Q_{\max }^{w} w \in W \\
q_{n}^{w} \geq 0 \\
n \in N^{*}, w \in W
\end{gathered}
$$

The meaning of the equations in Model (P1-4) is the same as that in Model (P1-2); the description is not repeated here.

\subsection{Design of Model-Solving Algorithm}

The solution of the bi-level programming model belongs to the NP-hard problem, the key to which is how to find out the concrete expression of the response function, so as to establish the relationship between the lower model and the upper model. In this paper, the sensitivity analysis method is used to solve the model. In the process of solving, the lower-level programming Model (L1-4) is expressed by Equation (29), which is the variational inequality for the objective function of Equation (26).

$$
\mathbf{f}\left(\mathbf{q}^{w *}\right)^{\mathrm{T}}\left(\mathbf{q}^{w}-\mathbf{q}^{w *}\right) \geq 0, w \in W
$$

where $\mathbf{q}^{w} \in\left\{\mathbf{q}^{w}||^{-w}=\left[\delta_{n}^{w}\right] \mathbf{q}^{w}, \mathbf{q}^{w} \geq 0\right\}$ and $\left[\delta_{n}^{w}\right]$ is the incidence matrix between the OD pair $w$ and the transportation mode $n$. We have:

$\delta_{n}^{w}=\left\{\begin{array}{c}1 \text { when there is a transportation mode } n \text { between the OD pair } w \\ 0 \quad \text { when there is not a transportation mode } n \text { between the OD pair } w\end{array}\right.$

$\mathbf{q}^{w *}$ represents the equilibrium solution of the lower-level model. The vector form of each variable is $\mathbf{q}^{w}=\left[q_{1}^{w}, q_{2}^{w}, \cdots, q_{n}^{w}\right]^{\mathrm{T}}, \mathbf{q}^{w *}=\left[q_{1}^{w *}, q_{2}^{w *}, \cdots, q_{n}^{w *}\right]^{\mathrm{T}}, \mathbf{f}\left(\mathbf{q}^{w *}\right)=\left[f_{1}\left(q_{1}^{w *}\right)\right.$, $\left.f_{2}\left(q_{2}^{w *}\right), \cdots, f_{n}\left(q_{n}^{w *}\right)\right]^{\mathrm{T}}, n \in N$, and $w \in W$. Taking the freight price vector $\mathbf{p}$ as the perturbation parameter of the variational inequality (Equation (29)) and $\mathbf{q}^{w}(\mathbf{p})$ as the function of $\mathbf{p}$, Equation (29) is transformed into Equation (30):

$$
\mathbf{f}\left(\mathbf{q}^{w *}(\mathbf{p}), \mathbf{p}\right)^{\mathrm{T}}\left(\mathbf{q}^{w}-\mathbf{q}^{w *}(\mathbf{p})\right) \geq 0, w \in W
$$

where for all $\mathbf{q}^{w}$, there is $\mathbf{q}^{w} \in\left\{\mathbf{q}^{w}(\mathbf{p})||^{-w}=\left[\delta_{n}^{w}\right] \mathbf{q}^{w}(\mathbf{p}), \mathbf{q}^{w}(\mathbf{p}) \geq 0\right\}$. Supposing that the variational inequality Equation (30) has a unique solution $\mathbf{q}^{w *}\left(\mathbf{p}_{(0)}\right)$ when $\mathbf{p}=\mathbf{p}_{(0)}$, the necessary conditions are as follows:

$$
\mathbf{f}^{w}\left(\mathbf{q}^{w *}(\mathbf{p}), \mathbf{p}\right)-\boldsymbol{\mu}^{w}=0, w \in W
$$




$$
\mathbf{Q}^{w}=\left[\delta_{n}^{w}\right] \mathbf{q}^{w *}(\mathbf{p}), w \in W
$$

where $\boldsymbol{\mu}^{w}$ is the Lagrangian multiplier vector of the freight volume constraint Equation (30). Setting $\mathbf{y}(\mathbf{p})=\left[\mathbf{q}^{w}(\mathbf{p}), \boldsymbol{\mu}^{w}(\mathbf{p})\right]^{\mathrm{T}}, \mathbf{J}_{\mathbf{y}}(\mathbf{p})$ represents the Jacobian matrix for Equations (31) and (32). $\mathbf{J}_{\mathbf{p}}(\mathbf{p})$ represents the Jacobian matrix for Equations (31) and (32) on $\mathbf{p}$. Then,

$$
\begin{gathered}
\nabla \mathbf{y}_{\mathbf{p}}(\mathbf{p})=\mathbf{J}_{\mathbf{y}}^{-1}(\mathbf{p})\left[-\mathbf{J}_{\mathbf{p}}(\mathbf{p})\right] \\
\mathbf{y}(\mathbf{p})=\left[\mathbf{q}^{w *}\left(\mathbf{p}_{(0)}\right), \boldsymbol{\mu}^{w *}\left(\mathbf{p}_{(0)}\right)\right]^{\mathrm{T}}+\left[\mathbf{J}_{\mathbf{y}}\left(\mathbf{p}_{(0)}\right)\right]^{-1}\left[-\mathbf{J}_{\mathbf{p}}\left(\mathbf{p}_{(0)}\right)\right] \cdot\left[\mathbf{p}-\mathbf{p}_{(0)}\right]
\end{gathered}
$$

In this paper, the railway freight pricing strategy $(n=1)$ is taken as an example to study. Setting $p_{1(0)}^{w}$ as the initial value of the railway transportation freight price for OD pair $w$, assuming that the freight prices of other transportation modes are fixed values, the freight volume $q_{1(0)}^{w *}\left(p_{1(0)}^{w}\right)$ of OD pair $w$ can be obtained by solving the lower-level programming model. The partial derivative relationship between railway freight volume and railway freight price is obtained as $\partial q_{1}^{w} / \partial p_{1}^{w}$; then, the linear approximate form of the response function is obtained by using Taylor expansion in Equation (35).

$$
q_{1}^{w}\left(p_{1}^{w}\right)=q_{1(0)}^{w *}\left(p_{1(0)}^{w}\right)+\frac{\partial q_{1}^{w}}{\partial p_{1}^{w}}\left(p_{1}^{w}-p_{1(0)}^{w}\right), w \in W
$$

Then, using the same algorithm, we can obtain the response function for other transportation modes, as per Equations (36) and (37).

$$
\begin{aligned}
& q_{2}^{w}\left(p_{1}^{w}\right)=q_{2(0)}^{w *}\left(p_{1(0)}^{w}\right)+\frac{\partial q_{2}^{w}}{\partial p_{1}^{w}}\left(p_{1}^{w}-p_{2(0)}^{w}\right), w \in W \\
& q_{3}^{w}\left(p_{1}^{w}\right)=q_{3(0)}^{w *}\left(p_{1(0)}^{w}\right)+\frac{\partial q_{3}^{w}}{\partial p_{1}^{w}}\left(p_{1}^{w}-p_{3(0)}^{w}\right), w \in W
\end{aligned}
$$

Equations (35) to (37) are used to calculate the total carbon emissions of a green freight system in the upper objective function. At this point, we have completed the solution of the bi-level programming model.

The specific steps of the algorithm are as follows:

Step 1: Parameter and variable initialization. The initial freight price $\left\{p_{n(0)}^{w} \mid n \in N\right.$, $w \in W\}$, the parameter value of the generalized cost function, the relevant parameters of the carbon emission calculation, the inverse demand function of the virtual transportation mode and the average freight cost and the upper limit of demand $Q_{\max }^{w}(w \in W)$ are set. The iteration number $j=0$ is recorded and the iteration precision $\varepsilon^{*}$ is set.

Step 2: Under the condition of $\left\{p_{n(j)}^{w} \mid n \in N, w \in W\right\}$ (the virtual transportation mode does not need pricing), the lower-level programming model is solved to obtain the freight volume allocation scheme $\left\{q_{n(j)}^{w *} \mid n \in N^{*}, w \in W\right\}$, including the equilibrium solution $\left\{q_{1(j)}^{w *}\right\}$ of the user equilibrium traffic assignment model.

Step 3: The derivative $\partial q_{n}^{w} / \partial p_{1}^{w}(n \in N, w \in W)$ of the freight volume of transportation mode $n$ to the disturbance parameter (railway freight price) under the condition of elastic demand is obtained by using the sensitivity analysis method, and the linear approximate expression of the reflection function is obtained according to Equations (35) to (37).

Step 4: The response function is substituted into the upper-level programming model, and the nonlinear optimization algorithm is used to obtain the new railway freight price $\left\{p_{1(j+1)}^{w} \mid n \in N, w \in W\right\}$. The upper objective function for the model is a nonlinear function, so we should pay attention to avoid local optimization when solving.

Step 5: Convergence judgment. If $\left|p_{1(j+1)}^{w}-p_{1(j)}^{w}\right| \leq \varepsilon^{*}(w \in W)$, the iteration accuracy is satisfied and the algorithm stops; otherwise, setting $j=j+1$, the iteration returns to Step 2 to continue, where $\varepsilon^{*}$ is the iteration precision parameter. 


\section{Numerical Examples}

In this paper, a transportation network with six OD pairs was established, in which the distance and transportation modes between each OD pair are marked, as shown in Figure 4. The number of OD pairs, the distance between each OD pair, and the transportation modes between each OD pair are shown in Figure 4.

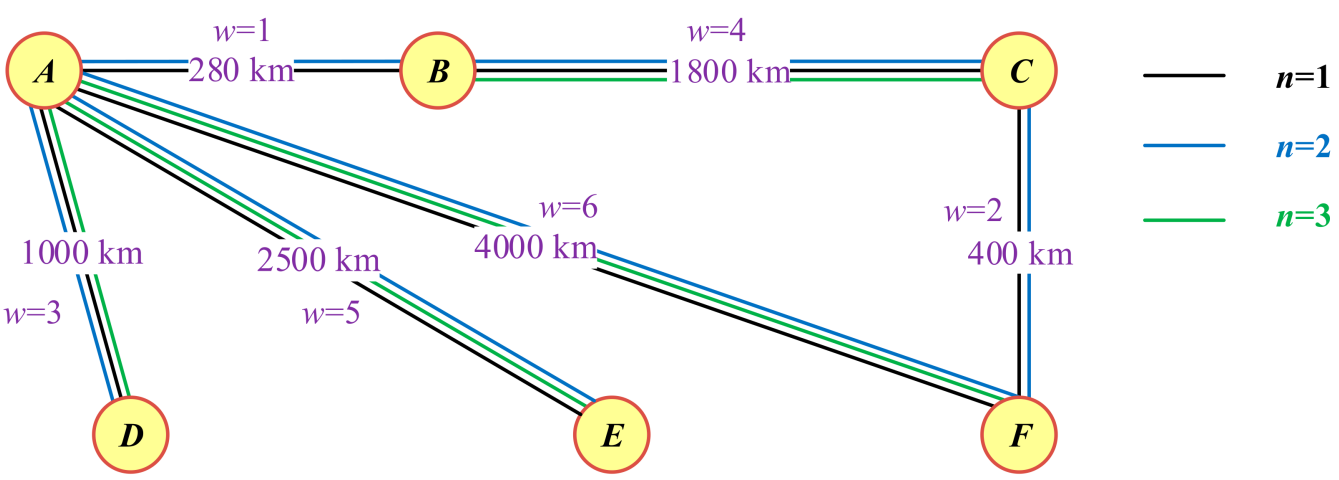

Figure 4. Transportation network for numerical example, including $w, l^{w}$, and $n$. Source: own elaboration.

The numbers of the OD pairs are given in Table 2, as are the names of the OD pairs, the distance value between each OD pair, and the transportation modes between each OD pair.

Table 2. Parameters of generalized cost.

\begin{tabular}{cccc}
\hline Number $w$ & OD Pair & Distance $\left.l^{w} \mathbf{( k m}\right)$ & Transportation Mode $n$ \\
\hline$w=1$ & AB & 280 & $\mathrm{n}=1,2$ \\
$w=2$ & CF & 400 & $\mathrm{n}=1,2$ \\
$w=3$ & AD & 1000 & $\mathrm{n}=1,2,3$ \\
$w=4$ & BC & 1800 & $\mathrm{n}=1,2,3$ \\
$w=5$ & AE & 2500 & $\mathrm{n}=1,2,3$ \\
$w=6$ & AF & 4000 & $\mathrm{n}=1,2,3$ \\
\hline
\end{tabular}

Source: Author's settings.

The generalized cost function for each transportation mode is shown in Equation (38).

$$
f_{n}^{w}\left(q_{n}^{w}\right)=\frac{1}{\tau} \ln q_{n}^{w}-L_{n}^{w}
$$

where $\tau$ is the undetermined parameter, $n \in N=\{1,2,3\}$ and $L_{n}^{w}$ is the utility function of the transportation mode $n$ between OD pair $w$. When the model is solved, it is assumed that the highway and air freight prices remain unchanged, the service attributes of different transportation modes remain unchanged, and the upper limit of the total transportation demand among cities is known and fixed. The known data and parameter settings are shown in Tables 3-5. 
Table 3. Parameters of different transportation modes (same values of different OD pairs).

\begin{tabular}{|c|c|c|c|}
\hline Transportation Mode & Railway $n=1$ & Highway $n=2$ & Air $n=3$ \\
\hline Price $p_{n}(\mathrm{CNY} / \mathrm{t} \cdot \mathrm{km})$ & $0.17 \leq p_{1} \leq 1.5$ & $p_{2}=0.50$ & $p_{3}=1.56$ \\
\hline Cargo damage rate $D_{n}$ & $D_{1}=0.002$ & $D_{2}=0.004$ & $D_{3}=0.001$ \\
\hline Overdue rate $G_{n}$ & $G_{1}=0.005$ & $G_{2}=0.006$ & $G_{3}=0.007$ \\
\hline Service quality $S_{n}$ & $S_{1}=7.5$ & $S_{2}=7.0$ & $S_{3}=8.5$ \\
\hline Environmental effect $Y_{n}$ & $Y_{1}=0.8$ & $Y_{2}=0.7$ & $Y_{3}=0.5$ \\
\hline Average freight cost $c_{n}(\mathrm{CNY} / \mathrm{t} \cdot \mathrm{km})$ & $c_{1}=0.15$ & / & / \\
\hline $\begin{array}{c}\text { Energy consumption intensity } \\
\theta_{n}\left(\mathrm{kgce} / 10^{4} \mathrm{t} \cdot \mathrm{km}\right)\end{array}$ & $\theta_{1}=85.4$ & $\theta_{2}=566.7$ & $\theta_{3}=5168.8$ \\
\hline Carbon emissions factor $\delta_{c}$ & $\delta_{c}=2.6$ & $\delta_{c}=2.6$ & $\delta_{c}=2.6$ \\
\hline $\begin{array}{l}\text { Carbon charge } \gamma_{(n)}^{w} \\
\text { Segment charging freight volume } a, b\end{array}$ & $\begin{array}{c}\gamma_{1}=0.01, \gamma_{2}=0.015, \gamma_{3}=0.018 \\
a=3000, b=7000\end{array}$ & $\begin{array}{c}\gamma_{1}=0.01, \gamma_{2}=0.015, \gamma_{3}=0.018 \\
a=3000, b=7000\end{array}$ & $\begin{array}{c}\gamma_{1}=0.01, \gamma_{2}=0.015, \gamma_{3}=0.018 \\
a=3000, b=7000\end{array}$ \\
\hline
\end{tabular}

Source: Author's settings.

Table 4. Parameters of different transportation modes (different values of different OD pairs).

\begin{tabular}{cccc}
\hline $\begin{array}{c}\text { Transportation } \\
\text { Mode }\end{array}$ & Railway $\boldsymbol{n}=\mathbf{1}$ & Highway $\boldsymbol{n = 2}$ & Air $\boldsymbol{n = 3}$ \\
\hline & $T_{1}^{1}=5.5 ; T_{1}^{2}=6.6 ;$ & $T_{2}^{1}=4.5 ; T_{2}^{2}=6.0 ;$ & $T_{3}^{3}=5.1 ;$ \\
Transportation time & $T_{1}^{3}=12.1 ; T_{1}^{4}=19.4 ;$ & $T_{2}^{3}=13.5 ; T_{2}^{4}=23.5 ;$ & $T_{3}^{4}=6.0 ; T_{3}^{5}=6.8 ; T_{3}^{6}=8.4$ \\
$T_{n}(\mathrm{~h})$ & $T_{1}^{5}=25.7 ; T_{1}^{6}=39.4$ & $T_{2}^{5}=32.3 ; T_{2}^{6}=51.0$ & \\
& $E_{1}^{1}=0.1 ; E_{1}^{2}=0.5 ;$ & $E_{2}^{1}=1 ; E_{2}^{2}=1 ;$ & $E_{3}^{1}=0 ; E_{3}^{2}=0 ;$ \\
Convenience $E_{n}$ & $E_{1}^{3}=0.75 ; E_{1}^{4}=0.75 ;$ & $E_{2}^{3}=0.85 ; E_{2}^{4}=0.85 ;$ & $E_{3}^{3}=0.9 ; E_{3}^{4}=0.9 ;$ \\
& $E_{1}^{5}=0.75 ; E_{1}^{6}=0.1$ & $E_{2}^{5}=0.1 ; E_{2}^{6}=0$ & $E_{3}^{5}=0.9 ; E_{3}^{6}=1$ \\
\hline Source: Author's settings. & & &
\end{tabular}

Table 5. Parameters of generalized cost.

\begin{tabular}{ccccc}
\hline Parameter & $\tau$ & $\alpha_{1}$ & $\alpha_{2}$ & $\alpha_{3} \sim \alpha_{7}$ \\
\hline Value & 1 & -3 & -0.02 & 0.45 \\
\hline Source: Author's settings. & & & &
\end{tabular}

The lower limit of the railway freight price is the railway freight cost $c_{1}$; then, we added carbon charges $\gamma_{(1)}^{w}$. In order to prevent 0 as a divisor in the process of calculation, which leads to errors in the program for solving the algorithm, we set the minimum value of $p_{1}^{w(\min )}$ as 0.17 , greater than $c_{1}+\gamma_{(1)}^{w}=0.168$. Let $\varepsilon^{*}=0.0001$ be the iterative precision of the sensitivity analysis-that is, when the difference between the two iterative results is less than 0.0001 , the iteration can be stopped, and the optimal solution is considered to be the acceptable optimal solution of the bi-level programming model. In order to solve the problem conveniently, this example assumes that the demand function is a linear function, $D\left(p_{n}^{w}\right)=10000-10 p_{n}^{w}$, and the inverse function of the demand function can be obtained as $D^{-1}\left(Q_{N}^{w}\right)=1000-0.1 Q_{N}^{w}$. Assuming that the upper limit of freight demand among cities is $Q_{\max }=10000 t$, according to the transformation method of elastic demand, the impedance function for the virtual transportation mode can be obtained as $f_{4}\left(q_{4}\right)=0.1 q_{4}$. The OD pair $w=4$ was taken as an example, and the calculation method for other OD pairs is the same. By substituting all the known data into the bi-level programming model, the following model can be obtained (omitting the superscript $w=4$ ). In order to prevent 0 as a divisor during calculation, we set $p_{1}^{w(\min )}=0.17$. We set the price limit on railways $(\mathrm{P} 1-5)$ as $p_{1}^{w(\max )}=1.5$.

$(\mathrm{M} 1-5)$

$\min U\left(p_{1}^{w}\right)=0.2 \cdot \frac{40.0 \times q_{1}\left(p_{1}\right)+265.2 \times q_{2}\left(p_{1}\right)+2419.0 \times q_{3}\left(p_{1}\right)-F_{\mathrm{I}}^{\min }\left(p_{n}^{w}\right)}{F_{\mathrm{I}}^{\max }\left(p_{1}\right)-F_{\mathrm{I}}^{\min }\left(p_{n}^{w}\right)}-0.8 \cdot \frac{q_{1}\left(p_{1}\right) \cdot\left(p_{1}-0.15-\gamma_{(1)}\right) \cdot l^{4}-F_{\mathrm{I}}^{\min }\left(p_{n}^{w}\right)}{F_{\mathrm{II}}^{\max }\left(p_{1}\right)-F_{\mathrm{I}}^{\min }\left(p_{n}^{w}\right)}$ 


$$
\begin{gathered}
\text { s.t. } 0.17 \leq p_{1} \leq 1.5 w \in W \\
p_{n} \geq 0 n \in N, w \in W \\
(\mathrm{~L} 1-5) \min Z\left(q_{n}\right)=\int_{0}^{q_{1}}\left(\ln q+3 p_{1}-4.58\right) d q+\int_{0}^{q_{2}}\left(\ln q+3 p_{2}-4.27\right) d q+\int_{0}^{q_{3}}\left(\ln q+3 p_{3}-5.23\right) d q+\int_{0}^{q_{4}} 0.1 q d q \\
\text { s.t. } \sum_{n=1}^{4} q_{n}=10000 n \in N^{*} \\
q_{n} \geq 0 \quad n \in N^{*}
\end{gathered}
$$

By substituting the initial values $p_{1(0)}=0.45, p_{2(0)}=0.5$, and $p_{3(0)}=1.56$ into the lower-level Model (L1-5), we can obtain the initial freight volume allocation scheme: $q_{1(0)}=5849.0, q_{2(0)}=3695.8, q_{3(0)}=400.8$, where $p_{2(0)}$ and $p_{3(0)}$ remain unchanged in the subsequent iterations. According to Step 1 to Step 5 in Section 5.3, the approximate relationship between freight volume and freight price can be obtained by Equation (45).

$$
\left[\begin{array}{l}
q_{1}(\mathbf{p}) \\
q_{2}(\mathbf{p}) \\
q_{3}(\mathbf{p})
\end{array}\right]=\left[\begin{array}{c}
5849.0 \\
3695.8 \\
400.8
\end{array}\right]+\left[\begin{array}{ccc}
-7237.9 & 6513.9 & 706.3 \\
6513.9 & -6971.4 & 446.3 \\
706.3 & 446.3 & -1153.9
\end{array}\right]\left[\begin{array}{l}
p_{1}-0.45 \\
p_{2}-0.50 \\
p_{3}-1.56
\end{array}\right]
$$

Based on this, the partial derivative $\partial q_{1(0)} / \partial p_{1(0)}=-7237.9$ of railway freight volume to railway freight price is obtained, and then, the linear approximate form of the railway transportation mode response function is obtained by Equation (46).

$$
q_{1(1)}\left(p_{1(1)}\right)=5849.0-7237.9 \cdot\left(p_{1(1)}-0.45\right)
$$

By analogy, the optimal solution of the objective function can be obtained by substituting the three approximate expressions $q_{1(1)}\left(p_{1(1)}\right), q_{2(1)}\left(p_{1(1)}\right)$, and $q_{3(1)}\left(p_{1(1)}\right)$ into the Objective Function (39) of the upper-level programming model. Then, according to Formula (3), we can find $\gamma_{(1)}=0.015$. We repeated the above iterative process with $p_{1(1)}=0.7700$ as the new initial value. Finally, after six iterations, the freight price of the

\begin{tabular}{|c|c|c|c|c|c|c|c|}
\hline OD Pair ID & Iterations & $\begin{array}{l}\text { Optimal Railway } \\
\text { Freight Price } \\
(\mathrm{CNY} / \mathrm{t} \cdot \mathrm{km})\end{array}$ & $\begin{array}{l}\text { Railway } \\
\text { Share(t) }\end{array}$ & $\begin{array}{c}\text { Highway } \\
\text { Share(t) }\end{array}$ & Air Share(t) & $\begin{array}{c}\text { Railway } \\
\text { EnterpriseProfit } \\
\text { (CNY) }\end{array}$ & $\begin{array}{c}\text { Total Carbon } \\
\text { Emissions } \\
\text { (kgce) }\end{array}$ \\
\hline$w=1$ & 7 & 0.7511 & 2858.2 & 7085.4 & / & 473,040 & 246,647 \\
\hline$w=2$ & 7 & 0.7691 & 3139.1 & 6804.6 & / & 764,807 & 326,536 \\
\hline$w=3$ & 6 & 0.7809 & 3355.1 & 6041.5 & 545.9 & $2,083,189$ & $3,024,561$ \\
\hline$w=4$ & 6 & 0.7844 & 3416.9 & 5885.8 & 638.2 & $3,839,476$ & $6,059,824$ \\
\hline$w=5$ & 5 & 0.8175 & 3935.0 & 5094.2 & 907.9 & $6,468,197$ & $10,448,552$ \\
\hline$w=6$ & 4 & 0.7950 & 3590.7 & 5024.3 & 1318.2 & $9,120,268$ & $23,176,105$ \\
\hline
\end{tabular}
railway transportation mode was 0.7844 ; there was no difference from the optimal solution 0.7844 of the fifth iteration $\left(0<\varepsilon^{*}\right)$. This met the iterative accuracy requirements and stopped the iteration. At this time, the railway freight price $p_{1(4)}=0.7844(\mathrm{yuan} / \mathrm{t} \cdot \mathrm{km})$ of OD pair $w=4$ is the acceptable optimal solution and the railway share is $3416.9 \mathrm{t}$. Similarly, the calculation results for other OD pairs are shown in Table 6.

Table 6. Numerical example results.

Source: Author's calculation.

\section{Discussion}

Through the simulation's net calculation of six OD pairs, we obtained the calculation results shown in Table 6 . The most significant difference among the OD pairs $w=1$ to $w=6$ is the difference in transport distance and the number of competitive modes of transport. Due to the obvious disadvantages of railway transportation and air transportation in "door- 
to-door" transportation, highway transportation has obvious advantages in short-distance transportation. Railway transportation and air transportation have more advantages in medium- and long-distance transportation. According to the industry statistical data and expert experience, we set the parameters of railway transportation, highway transportation, and air transportation as the basic data for the example analysis.

From the calculation results, it can be concluded that:

(1) In short-distance transportation (especially in transportation distances less than $500 \mathrm{~km})$, the highway transportation mode has obvious advantages $\left(q_{2}^{1}=7085.4, q_{2}^{2}=6804.6\right.$, about $70 \%$ of the total freight volume), and the freight share is obviously better than the railway transportation mode. With the increase in transportation distance, the freight share for highway transportation decreases.

(2) The competitive advantage of railway freight transportation is obvious at a distance of about 1500 to $2000 \mathrm{~km}$, while for short-distance transportation of less than $500 \mathrm{~km}$, although the price of railway freight transportation has been reduced, it is still at a competitive disadvantage compared with highway transportation. Just as in OD pair $w=5$, the price of railway transportation is $0.8175 \mathrm{CNY} / \mathrm{t} \cdot \mathrm{km}$, and the railway share is $3935 \mathrm{t}$. After the price reduction, in OD pair $w=4$, the price of railway transportation is 0.7844 $\mathrm{CNY} / \mathrm{t} \cdot \mathrm{km}$, and the railway share is $3416.9 \mathrm{t}$. The price of railway transportation decreased obviously, but it did not lead to an increase in railway transportation share. The same results were obtained for OD pair $w=3$.

(3) For air transportation, in long-distance transportation of more than $2000 \mathrm{~km}$, its transportation advantage increases significantly. Even if other transportation modes reduce their transportation prices, such as the railway transportation price reducing from $0.8175 \mathrm{CNY} / \mathrm{t} \cdot \mathrm{km}$ to $0.7950 \mathrm{CNY} / \mathrm{t} \cdot \mathrm{km}$, the freight share of air transportation still increases significantly, from 907.9 t to $1318.2 \mathrm{t}$, increasing by $45.19 \%$.

(4) Considering the impact of freight price on enterprise profits, through freight price adjustment, when the transportation distance increases from 280 to $400 \mathrm{~km}$ (1.43 times), the profit for railway transportation enterprises increases from $473,040 \mathrm{CNY}$ to $764,807 \mathrm{CNY}$ (1.6 times), which indicates that price adjustment is conducive to the increase in enterprise income. The same results can be obtained in other OD pairs. In addition, total carbon emissions increased from 246,647 kgce to 326,536 kgce (1.3 times), less than the growth of the transportation distance. This shows that price adjustment plays a positive role in optimizing transportation structure and reducing carbon emissions. However, with the increase in the air transportation mode, the carbon emissions of the freight system have been greatly improved. Therefore, it is necessary to promote the development of green freight modes.

(5) From the results of the example analysis, we can see that, for different modes of transportation, there is no inevitable relationship between the transportation price and the freight market share. In order to maximize the efficiency of the whole freight system and establish a reasonable division of transportation modes, it is necessary to reasonably judge the advantageous transportation distance of different transportation modes. A reasonable transportation price should be determined corresponding to the advantageous transportation distance of different transportation modes. Only in this way can we maximize the operating profit of logistics enterprises and establish a reasonable transportation structure.

\section{Conclusions}

Considering the impact of COVID-19 on the capital chain of logistics enterprises and of carbon emissions on the green freight transport system, a multi-objective bi-level programming model was proposed for the study of green freight pricing strategies. The research results are as follows.

Firstly, by constructing a bi-level programming model to consider the market competition for different transportation modes, we provided a freight transportation pricing method considering the freight volume distribution among different transportation modes. 
Compared with existing studies, such as in references [3-7], only the competition among different logistics enterprises in a certain transportation mode was considered, and there exists a lack of consideration of overall market competition.

Secondly, in order to obtain the cargo flow assignment of different transportation modes, we referred to the user equilibrium assignment model, which has been widely used in passenger traffic flow allocation, designed a generalized cost function for different transportation modes, and set the parameters of the generalized cost function according to the characteristics of the different transportation modes. As research on generalized cost functions for freight transportation is rare, and the establishment of the assumption of elastic demand renders our research closer to the actual operation of the freight market, we have provided a new research direction for future studies.

Thirdly, the references [22-24,26,27] performed comprehensive studies on transportation pricing, considering carbon emissions, and on the charging parameters for carbon emissions. However, research on the carbon emissions of cargo transportation that considers the competition between different transportation modes is relatively rare. In order to promote green development, China has proposed a national strategy of adjusting transportation structure. Only on the basis of considering the distribution of freight volume among different transportation modes can we optimize the national transportation structure through the adjustment of freight price. Contemporary research on the carbon emissions of a single transportation mode is difficult to use for the optimization of transportation structure. Adjusting the freight volume among different transportation modes through the change of transportation price is one of the biggest contributions of this paper.

Finally, the purpose of this paper was to maximize enterprise operating profits, which can ensure the survival of logistics enterprises during the pandemic period. In references [37-39], methods of supply chain reconfiguration during the COVID-19 pandemic period were proposed. However, the reconfiguration of supply chain network structure often has a long implementation cycle and large initial investment, which suggests higher requirements for enterprise cash flow. Compared with the existing research, our study can improve enterprise profits through a quantitative price strategy, which is easier to operate, and the effect realization cycle is short, which is conducive to the rapid improvement of enterprises' competitive and survival ability in the short term.

There are still some limitations in this paper. We have provided a concept for the establishment of a multi-objective bi-level programming model for enterprise pricing, which takes into account both enterprise profits and the carbon emissions of the transportation system. However, in the parameter design of this paper, there are few references. If we want to make our study more closely reflect the actual situation, we need to carry out more case studies and parameter adjustment test experiments.

In future research, the design of parameters for this model can be further studied, and following the COVID-19 pandemic, sociotechnical transitions, transportation mode transitions, and energy consumption structure adjustment will bring great changes to our lives [51]. The optimization of transportation organization can only play a minor role in reducing the carbon emissions of a freight transportation system. To reduce the carbon emissions of transportation sharply, the world's major economies need to actively promote the use of green renewable energy, such as bioenergy and solar energy [44,45]. Only by solving the fundamental problem of energy use can we promote the green development of transportation systems and protect our living environment.

Author Contributions: Modeling, methodology, software, validation, data curation, investigation, resources, writing—original draft preparation and editing, programming, D.W., L.Z., H.Z., X.L.; project administration, L.Z., X.L.; funding acquisition, L.Z., X.L.; program debugging, language refinement, H.Z. All authors have read and agreed to the published version of the manuscript.

Funding: This research was funded by the National Key R\&D Program of China (2018YFB1601303) and Scientific research projects of the China Academy of Railway Sciences Group Co., Ltd. (2020YJ196).

Institutional Review Board Statement: Not applicable. 
Informed Consent Statement: Not applicable.

Data Availability Statement: The data presented in this study and the simulation source program of the example are available on request from the corresponding author. Some of the data are not publicly available due to privacy restrictions.

Conflicts of Interest: The authors declare no conflict of interest.

\section{References}

1. Liu, Z.; Li, L.; Zhang, Y. Investigating the $\mathrm{CO}_{2}$ Emission Differences among China's Transport Sectors and Their Influencing Factors. Nat. Hazards 2015, 77, 1323-1343. [CrossRef]

2. Luo, X.; Zhang, S.; Bian, X.; Zhang, W. Carbon Footprint Estimation of Transportation Industry in China. J. Jiangsu Univ. 2012, 33, 120-124. [CrossRef]

3. Wang, W.; Wang, S.; Peng, Y.; Xu, X. Pricing Game Model of Competitive Port Integrating Highway Transportation Service. J. Transp. Syst. Eng. Inf. Technol. 2018, 18, 229-235. [CrossRef]

4. Xiao, F.; Liu, X. Pricing Strategy of Maritime Transportation Cost based on Revenue Management and Empty Container Theory. J. Coast. Res. 2019, 98, 121-124. [CrossRef]

5. Arbib, C.; Pınar, M.Ç.; Tonelli, M. Competitive Location and Pricing on a Line with Metric Transportation Costs. Eur. J. Oper. Res. 2020, 282, 188-200. [CrossRef]

6. Song, W.; Zhao, P.; Li, B.; Wang, P. Robust Optimization Model of Dynamic Pricing for High-speed Railway. J. Harbin Inst. Technol. 2018, 50, 25-30. [CrossRef]

7. Zeng, Q.; Yue, A.; Sun, H.; Chen, C. A Pricing Model for the Container Liner Shipping based on Price Matching Policies. Syst. Eng.-Theory Pract. 2017, 37, 2366-2372. [CrossRef]

8. Guo, C. Study on Improvement of Common Railway Passenger Fare System. Traffic Transp. 2010, 12, 88-90.

9. Ye, Y.; Cheng, Z. Fares and Transport Needs on the Condition of Multi-mode Traffic on Passenger Transportation Corridors. Urban Mass Transit 2011, 14, 32-36. [CrossRef]

10. Bliemer, M.; Bovy, P. Impact of Route Choice Set on Route Choice Probabilities. Transp. Res. Rec. J. Transp. Res. Board 2008, 2076, 10-19. [CrossRef]

11. Alivand, M.; Hochmair, H.; Srinivasan, S. Analyzing how Travelers Choose Scenic Routes Using Route Choice Models. Comput. Environ. Urban Syst. 2015, 50, 41-52. [CrossRef]

12. Lin, W. Research on Tolling Strategy of Intercity Expressways; Chang'an University: Xi'an, China, 2013.

13. Tuffin, B.; Cadre, H.; Bouhtou, M. Optimal Pricing Strategy with Compensation when QoS is not Satisfied. Ann. Telecommun.-Ann. TÉLÉCommun. 2010, 65, 163-170. [CrossRef]

14. Ren, S.; Fu, F.; Schaar, M. Traffic-Dependent Pricing for Delay-Sensitive Multimedia Networks. In Proceedings of the 2011 IEEE Global Telecommunications Conference (GLOBECOM 2011), Houston, TX, USA, 5-9 December 2011. [CrossRef]

15. Kirschstein, T.; Meisel, F. GHG-emission Models for Assessing the Eco-friendliness of Road and Rail Freight Transports. Transp. Res. Part B Methodol. 2015, 73, 13-33. [CrossRef]

16. Chen, L.; Yang, H. Managing Congestion and Emissions in Road Networks with Tolls and Rebates. Transp. Res. Part B Methodol. 2012, 46, 933-948. [CrossRef]

17. Zhang, X.; Li, L. An Integrated Planning/Pricing Decision Model for Rail Container Transportation. Int. J. Civ. Eng. 2019, 17, 1537-1546. [CrossRef]

18. Wang, Y.; Che, T.; Yan, S.; Zhang, P. A Bi-level Programming Model for Airline's Hub-and-spoke Route Network Design. Technol. Econ. Areas Commun. 2020, 22, 8-15. [CrossRef]

19. Zhang, X.; Li, L.; Zhang, J. An Optimal Service Model for Rail Freight Transportation: Pricing, Planning, and Emission Reducing. J. Clean. Prod. 2019, 218, 565-574. [CrossRef]

20. Jia, L.; Alizadeh, R.; Hao, J.; Wang, G.; Mistree, F. A Rule-based Method for Automated Surrogate Model Selection. Adv. Eng. Inform. 2020, 45, 101123. [CrossRef]

21. Alizadeh, R.; Allen, J.K.; Mistree, F. Managing Computational Complexity Using Surrogate Models: A Critical Review. Res. Eng. Des. 2020, 31, 275-298. [CrossRef]

22. Chang, T.H.; Tseng, J.S.; Hsieh, T.H.; Hsu, Y.T.; Lu, Y.C. Green Transportation Implementation through Distance-based Road Pricing. Transp. Res. Part A Policy Pract. 2018, 111, 53-64. [CrossRef]

23. Saharan, S.; Bawa, S.; Kumar, N. Dynamic Pricing Techniques for Intelligent Transportation System in Smart Cities: A Systematic Review. Comput. Commun. 2020, 150, 603-625. [CrossRef]

24. Williams, J.; Alizadeh, R.; Allen, J.K.; Mistree, F. Using Network Partitioning to Design a Green Supply Chain. In Proceedings of the ASME 2020 International Design Engineering Technical Conferences and Computers and Information in Engineering Conference, St. Louis, MO, USA, 17 August 2020.

25. Lv, J. Research on Charging Model for Tradable Credit Scheme Considering Carbon Emission; Jilin University: Jilin, China, 2020.

26. Han, P.; Cai, Q.; Oda, T.; Zeng, N.; Liu, D. Assessing the recent impact of COVID-19 on carbon emissions from China using domestic economic data. Sci. Total Environ. 2021, 750, 141688. [CrossRef] [PubMed] 
27. Shan, Y.; Ou, J.; Wang, D.; Zeng, Z.; Hubacek, K. Impacts of COVID-19 and Fiscal Stimuli on Global Emissions and the Paris Agreement. Nat. Clim. Chang. 2021, 11, 1-7. [CrossRef]

28. Zandi, G.; Shahzad, I.; Farrukh, M.; Kot, S. Supporting Role of Society and Firms to COVID-19 Management among Medical Practitioners. Int. J. Environ. Res. Public Health 2020, 17, 7961. [CrossRef] [PubMed]

29. Končar, J.; Grubor, A.; Marić, R.; Vučenović, S.; Vukmirović, G. Setbacks to IoT Implementation in the Function of FMCG Supply Chain Sustainability during COVID-19 Pandemic. Sustainability 2020, 12, 7391. [CrossRef]

30. Ursachi, C.S.; Munteanu, F.D.; Cioca, G. The Safety of Slaughterhouse Workers during the Pandemic Crisis. Int. J. Environ. Res. Public Health 2021, 18, 2633. [CrossRef] [PubMed]

31. Zafar, M.Z.; Maqbool, A.; Cioca, L.I.; Shah, S.G.M.; Masud, S. Accentuating the Interrelation between Consumer Intention and Healthy Packaged Food Selection during COVID-19: A Case Study of Pakistan. Int. J. Environ. Res. Public Health 2021, 18, 2846. [CrossRef]

32. Park, H.; Bae, S. Quantitative Assessment of Energy Supply Security: Korea Case Study. Sustainability 2021, 13, 1854. [CrossRef]

33. International Monetary Fund. World Economic Outlook (International Monetary Fund) April 2021. Available online: https: //www.imf.org/en/Publications/WEO/Issues/2021/03/23/world-economic-outlook-april-2021 (accessed on 29 April 2021).

34. International Monetary Fund. World Economic Outlook (International Monetary Fund) October 2010. Available online: https: //www.imf.org/en/Publications/WEO/Issues/2016/12/31/Recovery-Risk-and-Rebalancing (accessed on 29 April 2021).

35. International Air Transport Association. IATA Annual Review 2020. Available online: https://www.iata.org/contentassets/c812 22d96c9a4e0bb4ff6ced0126f0bb/iata-annual-review-2020.pdf (accessed on 30 April 2021).

36. Fu, J. The 'Dark Hour' of Aviation Industry is Still Going On, How Do International Express Giants Deal with It. Available online: https:/ / m.thepaper.cn/baijiahao_11500042 (accessed on 30 April 2021).

37. Shahed, K.S.; Azeem, A.; Ali, S.M.; Moktadir, M.A. A Supply Chain Disruption Risk Mitigation Model to Manage COVID-19 Pandemic Risk. Environ. Sci. Pollut. Res. 2021, 1, 1-16. [CrossRef]

38. Ivanov, D. Viable Supply Chain Model: Integrating Agility, Resilience and Sustainability Perspectives-Lessons from and Thinking beyond the COVID-19 Pandemic. Ann. Oper. Res. 2020. [CrossRef]

39. Karmaker, C.L.; Ahmed, T.; Ahmed, S.; Ali, S.M.; Moktadir, M.A.; Kabir, G. Improving Supply Chain Sustainability in the Context of COVID-19 Pandemic in an Emerging Economy: Exploring Drivers using an Integrated Model. Sustain. Prod. Consum. 2021, 26, 411-427. [CrossRef] [PubMed]

40. Sarkis, J. Supply Chain Sustainability: Learning from the COVID-19 Pandemic. Int. J. Oper. Prod. Manag. 2020, 41, 63-73. [CrossRef]

41. National Bureau of Statistics. National Data. Available online: https:/ / data.stats.gov.cn/easyquery.htm? $\mathrm{cn}=\mathrm{C} 01$ (accessed on 30 April 2021).

42. Elliott, R.J.; Schumacher, I.; Withagen, C. Suggestions for a COVID-19 Post-Pandemic Research Agenda in Environmental Economics. Environ. Resour. Econ. 2020, 76, 1187-1213. [CrossRef] [PubMed]

43. Department of Energy Statistics, National Bureau of Statistics. China Energy Statistical Yearbook; China Statistics Press: Beijing, China, 2020.

44. Alizadeh, R.; Lund, P.D.; Soltanisehat, L. Outlook on Biofuels in Future Studies: A Systematic Literature Review. Renew. Sustain. Energy Rev. 2020, 134, 110326. [CrossRef]

45. Alizadeh, R.; Soltanisehat, L.; Lund, P.D.; Zamanisabzi, H. Improving Renewable Energy Policy Planning and Decision-making through a Hybrid MCDM Method. Energy Policy 2020, 137, 111174. [CrossRef]

46. Alizadeh, R.; Beiragh, R.G.; Soltanisehat, L.; Soltanzadeh, E.; Lund, P.D. Performance Evaluation of Complex Electricity Generation Systems: A Dynamic Network-based Data Envelopment Analysis Approach. Energy Econ. 2020, 91, 104894. [CrossRef]

47. Long, N.; Moseson, A.J.; Farnam, Y.; Spatari, S. Effects of Composition and Transportation Logistics on Environmental, Energy and Cost Metrics for the Production of Alternative Cementitious Binders. J. Clean. Prod. 2018, 185, 628-645. [CrossRef]

48. Ebrahimi, P.R.; Alizadehsalehi, S.; Mosaberpanah, M.A. Interactions of Sustainability and BIM in Support of Existing Buildings. In Proceedings of the International Conference on Sustainable Infrastructure 2019, Los Angeles, CA, USA, 6-9 November 2019. [CrossRef]

49. Brumercikova, E.; Sperka, A. Problems of Access to Services at Railway Stations in Freight Transport in the Slovak Republic. Sustainability 2020, 12, 8018. [CrossRef]

50. Xu, Z.; Chen, D. Analysis of Ramp Design and Optimization of Urban Expressway Based on Bi-level Programming Model. J. Transp. Eng. Inf. 2011, 9, 84-91. [CrossRef]

51. Wells, P.; Abouarghoub, W.; Pettit, S.; Beresford, A. A Socio-technical Transitions Perspective for Assessing Future Sustainability Following the COVID-19 Pandemic. Sustain. Sci. Pract. Policy 2020, 16, 29-36. [CrossRef] 